\title{
Individual differences in location memory
}

\author{
JAMES M. O'DEKIRK, BEVERLY S. WYATT, and NORMAN R. ELLIS \\ University of Alabama, Tuscaloosa, Alabama
}

\begin{abstract}
The stability of individual differences in memory for location was assessed over a 1-week period. Subjects looked through a picture book and then relocated the pictures on the pages. This was repeated a week later with new pictures. The test-retest correlation was 0.60 , indicating stable individual differences in this automatically processed task.
\end{abstract}

Hasher and Zacks $(1979,1984)$ have proposed that the encoding of temporal order, frequency of occurrence, and spatial location are automatic processes that are biologically prewired in the individual. Since these processes are not affected by such variables as age, intelligence, or social class, they should show minimal individual differences. Hunt (1978), on the other hand, hypothesized that there should be consistent individual differences in automatic processing. He believed that controlled, or effortful, processes were less stable than were automatic processes.

Consistent with Hunt (1978), Ellis, Woodley-Zanthos, and Dulaney (1989) reported individual differences in the processing of memory for spatial location. They tested the reliability of automatic processing by comparing memory on a spatial location task across a 3-month period in a group of Down's syndrome subjects and found that location memory was consistent within individuals from one session to the next. Each session consisted of the subjects viewing 60 pictures arranged in a picture book, with a picture in each of the four quadrants of a page. The pictures were photographs of common objects (e.g., a car, a fork, a bar of soap). After viewing the pictures, the subject was given 4 min for recall. Following this, a location memory task required the subject to relocate the picture on a blank grid similar to a page of the picturebook. The same procedure was conducted in a follow-up study 3 months later on 32 of the original 36 subjects. The correlation between the two sessions for relocation scores was $.75(p<.01)$. This contrasted with a correlation of $.35(p<.05)$ for picture recall.

The present study extends this earlier work by assessing the reliability of individual differences in encoding spatial location among college students over a 1-week period. We attempted to vary motivation in order to observe consistency in performance under more optimal conditions. Half of the subjects received payment for their participation; the other subjects were required to partici-

This research was supported by Grant No. HD15558 from the National Institute of Child Health and Human Development to the third author. This study was based on a master's thesis submitted to the University of Alabama by the first author. Requests for reprints should be sent to Norman R. Ellis, Department of Psychology, University of Alabama, Box 870348, Tuscaloosa, AL 35487-0348. pate for class credit. The paid group was expected to show less error variance from one test to the other than was the class-credit group. The more highly motivated subjects were expected to pay more attention to the task and therefore recognize more pictures. But, since memory for location is automatic, the proportion of pictures relocated accurately should not vary with level of motivation.

\section{METHOD}

\section{Subjects}

Sixty-four students were recruited as subjects from undergraduate classes, through the university newspaper, and through the university student employment office. The 32 subjects recruited from classes were given course credit for their participation; the 32 subjects recruited through the newspaper and the employment office were paid $\$ 10.00$ $\$ 14.70$, depending on their performance, for each of two experimental sessions.

\section{Materials}

Forty-two posters, each with 4 pictures, were used for each session. The posters were $41 \times 54 \mathrm{~cm}$ and were made out of black posterboard that was divided into four quadrants with white tape. A picture $(17 \times 22 \mathrm{~cm})$ was placed in the middle of each of the four quadrants. In Session 1, the subjects were given a practice task in which they saw 20 pictures on 5 posters. Five of the pictures and 5 new (distractor) pictures were used in a recognition test. In the main task, they saw a study set of 168 pictures on 42 posters. The recognition test included 42 of these pictures along with 42 distractors randomly drawn from the same pool. In Session 2, the subjects were given a task identical to that given in Session 1, except that new pictures were used. A practice task was not given in Session 2. Two study sets and two test forms were counterbalanced so that they occurred equally often in the two sessions. The posters were set upright on a table; a blank cover poster was used to prevent the subject from viewing the first pictures until the experiment began.

\section{Procedure}

The subjects were given typed instructions that described the experimental procedure and fully informed them of the memory tests. The practice task followed.

In the main task, the experimenter exposed each poster to the subject for $10 \mathrm{sec}$. After viewing all of the posters, the subjects were handed a set of 84 pictures, which they were to sort into "old" pictures (ones they had seen on the poster) and "new" pictures (ones they had not seen on the posters). Half of the pictures were old, and half were new. Approximately 2 min later, the location memory test was given. The subject indicated the location of the pictures on a blank poster. Only the pictures that a subject had recognized as targets were included in the test set. Similar tests were given 7 days later, but with a different set of pictures. 
At the conclusion of Session 2, the subjects received either class credit or payment. The half that received payment were paid $5 \notin$ for every correct response in the recognition test and 254 for every correct response in the location test, which amounted to an average of $\$ 10$ for their participation.

\section{RESULTS}

The dependent variables were hits, false alarms, $d^{\prime}$, and the proportion of correct relocations. Means and standard deviations of these measures are presented in Table 1.

An independent groups $t$ test determined that the two test forms did not result in differences in location scores. Likewise, a repeated measures $t$ test showed that the picture sets did not differ significantly.

A 2 (motivation group) $\times 2$ (test session) analysis of variance was conducted for hits, false alarms, $d^{\prime}$, and the proportion of correct relocations. The results revealed a significant main effect for hits between groups $[F(1,62)=$ 4.18, $\left.M S_{\mathrm{e}}=0.012, p<.05\right]$. There were no statistically significant effects in the analyses of false alarms, $d^{\prime}$, or relocation scores.

Within the paid and volunteer groups, Pearson productmoment correlation coefficients were computed between the scores of the two test sessions for each dependent measure. These correlations are presented in Table 2 . None of the correlations between test sessions for any of the dependent measures differed significantly between the paid and volunteer groups.

All of the correlation coefficients, except those for false alarms, differed significantly from zero $(p<.05)$. The correlation between test sessions for the relocation scores of the combined paid and volunteer groups was .60.

\section{DISCUSSION}

These results add support to those obtained by Ellis et al. (1989), who found significant reliability for location memory in Down's syndrome subjects between two test sessions separated by 3 months. Their obtained correlation of .75 showed that individual differences in relocation scores were consistent between the two test sessions. The present study, likewise, found a significant test-retest correlation of .60 in combined groups of college students. These individual differences in encoding memory for spatial location appear to be consistent, and these consistencies can be generalized to both normal and mentally retarded persons.

These results also show that there are no differences between the paid group and the volunteer group. However, there does appear to be a trend in the expected direction. This is shown by the significant main effect for hits across groups presented in Table 1 and by the higher correlations between $d^{\prime}$ and the proportion of correct relocations for the paid
Table 2

Pearson Product-Moment Correlations Between the Two Test Sessions

\begin{tabular}{lcc}
\hline & \multicolumn{2}{c}{ Group } \\
\cline { 2 - 3 } \multicolumn{1}{c}{ Variable } & Paid & Volunteer \\
\hline Hits & .877 & .816 \\
False Alarms & .075 & .067 \\
Relocations & .638 & .555 \\
$d^{\prime}$ & .687 & .385 \\
\hline
\end{tabular}

group. For Session 1, the correlations between $d^{\prime}$ and relocation accuracy for the paid group and the volunteer group were .61 and .30 , respectively. The correlations for Session 2 were .64 and .27 , respectively. Since the paying subjects did not significantly increase their motivation over that of the volunteer subjects, we could not test the hypothesis that the proportion of pictures relocated would be invariate for different levels of recognition accuracy.

Hasher and Zacks $(1979,1984)$ assumed that location memory is a process that is biologically based. They proposed that individual differences such as age, social class, and intelligence would show little, if any, effect on the more primitive functions of the brain such as the encoding of locations. An alternative hypothesis proposed by Ellis et al. (1989) agrees that age, intelligence, and social class should show little influence but suggested that automatic processes would reflect biologically based individual differences.

The procedure used in this experiment, adopted from Von Wright, Gebhard, and Karttunen (1975), minimizes effortful processing. Previous studies of memory for location using this procedure have shown that there are no developmental differences after 3-4 years of age (Ellis, Katz, \& Williams, 1987; Ellis et al., 1989) and no differences due to intelligence (Ellis et al., 1987; Ellis et al., 1989); nor are there effects caused by type of instruction (Ellis, 1990; Ellis et al., 1987; Ellis \& Rickard, 1989; Ellis et al., 1989), practice (Ellis, 1990), or concurrent processing (Ellis, 1990). The present study shows that both recognition memory and memory for locations reflect a rather stable characteristic of a person. The correlation of hits from one session to another was .85 ; the correlation for location accuracy was .60 , after adjustment for recognition accuracy. In our view, this reflects consistent individual differences in processes that are relatively immune to influence from experiential variables.

\section{REFERENCES}

EluIs, N. R. (1990). Is memory for spatial location automatically encoded? Memory \& Cognition, 18, 584-592.

Ellis, N. R., Katz, E., \& Williams, J. E. (1987). Developmental aspects of memory for spatial location. Journal of Experimental Child Psychology, 44, 401-412.

EluIs, N. R., \& RickARD, T. C. (1989). The retention of automatically and effortfully encoded stimulus attributes. Bulletin of the Psychonomic Society, 27, 299-302.

Ellis, N. R., Woodley-Zanthos, P., \& Dulaney, C. L. (1989). Memory for spatial location in children, adults, and mentally retarded persons. American Journal on Mental Retardation, 93, 521-527.

Table 1

Mean Proportions and Standard Deviations (SDs) of Hits, False Alarms, Relocations, and $d^{\prime}$

\begin{tabular}{|c|c|c|c|c|c|c|c|c|}
\hline \multirow[b]{2}{*}{ Group } & \multicolumn{2}{|c|}{ Hits } & \multicolumn{2}{|c|}{$\begin{array}{c}\text { False } \\
\text { Alarms }\end{array}$} & \multicolumn{2}{|c|}{ Relocations } & \multicolumn{2}{|c|}{$d^{\prime}$} \\
\hline & $M$ & $S D$ & $M$ & $S D$ & $\boldsymbol{M}$ & $S D$ & $\boldsymbol{M}$ & $S D$ \\
\hline $\begin{array}{l}\text { Paid } \\
\text { Volunteer }\end{array}$ & $\begin{array}{l}0.872 \\
0.833\end{array}$ & $\begin{array}{l}0.096 \\
0.085\end{array}$ & $\begin{array}{l}0.068 \\
0.067\end{array}$ & $\begin{array}{l}0.071 \\
0.077\end{array}$ & $\begin{array}{l}0.695 \\
0.665\end{array}$ & $\begin{array}{l}0.125 \\
0.111\end{array}$ & $\begin{array}{l}2.906 \\
2.690\end{array}$ & $\begin{array}{l}0.757 \\
0.616\end{array}$ \\
\hline
\end{tabular}


Hasher, L., \& ZACKs, R. T. (1979). Automatic and effortful processes in memory. Journal of Experimental Psychology: General, 108, 356-388.

HASHER, L., \& ZACKS, R. T. (1984). Automatic processing of fundamental information: The case of frequency of occurrence. American Psychologist, 39, 1372-1388.

Hunt, E. (1978). Mechanics of verbal ability. Psychological Review, 85, $109-130$.
Von Wright, J. M., Gebhard, P., \& Karttunen, M. (1975). A developmental study of the recall of spatial location. Journal of Experimental Child Psychology, 20, 181-190.

(Manuscript received July 8, 1992.) 